Pacific Journal of Mathematic 


\title{
LUSIN AREA FUNCTIONS ON LOCAL FIELDS
}

\author{
JIA-ARNG CHAO
}

We show that over a local field, Lusin area functions and nontangential maximal functions of a regular function are equivalent in the $L^{p}$ "norm" for $0<p<\infty$. As a consequence, we have that "nice" singular integral transforms preserve $H^{p}$-spaces for $0<p<\infty$.

1. By a local field, we mean a locally compact, nondiscrete, totally disconnected, (complete) field. Various aspects of harmonic analysis on local fields have been studied. A list of references can be found in [4]. We also refer to [4] for notation and preliminaries.

Let $K$ be a fixed local field with the ring of integers $\mathscr{O} \cdot \mathscr{O} / \mathscr{P} \cong$ $G F(q)$ where $\mathscr{P}$ is the maximal ideal in $\mathscr{O}$ and $q$ is a prime power. For $k \in Z$, let $\mathscr{P}^{-k}=\left\{x \in K:|x| \leqq q^{k}\right\},\left(\mathscr{O}=\mathscr{P}^{0}\right) . \quad \mathscr{P}_{y}^{-k}=y+\mathscr{P}^{-k}$ are spheres. The Haar measure on $K$ has been normalized so that $|\mathscr{O}|=\int_{0} d x=1$ and $\left|\mathscr{P}_{y}^{-k}\right|=q^{k}$ for all $k$. The theory of regular functions which are the local field analogue of harmonic functions is studied in [10] and [4]. In particular, distributions on $K$ have been identified with regular functions on $K \times \boldsymbol{Z}$ and the regularization kernel $R_{k}(x)=q^{-k} \Phi_{-k}(x)$, where $\Phi_{-k}$ is the characteristic function of $\mathscr{P}^{-k}$, serves as the Poisson kernel.

Write $\left(\mathscr{P}_{y}^{-l}, k\right)=\left\{(x, k) \in K \times Z: x \in \mathscr{P}_{y}^{-l}\right\}$. For a nonnegative integer $l$ and $z \in K$, let $\Gamma_{l}(z)=\left\{(x, k) \in K \times Z:|x-z| \leqq q^{k+l}\right\}=$ $\mathrm{U}_{k}\left(\mathscr{P}_{z}^{-(k+l)}, k\right)$. For a distribution $f$ on $K$ or a regular function $f(x, k)$ on $K \times Z$, denote $d_{k} f(x)=f(x, k)-f(x, k+1)$. The Lusin area function of $f$ with respect to $\Gamma_{l}$ is given by

$$
S^{(l)} f(z)=\left(\sum\left|d_{k} f(x)\right|^{2}\right)^{1 / 2}
$$

where the sum runs over distinct $\left(\mathscr{P}_{x}^{-k}, k\right) \subset \Gamma_{l}(z)$. Write $S f(z)=$ $S^{(0)} f(z)=\left(\sum_{k}\left|d_{k} f(z)\right|^{2}\right)^{1 / 2}$. The nontangential maximal function of $f$ with respect to $\Gamma_{l}$ is given by

$$
m^{(l)} f(z)=\sup _{(x, k) \in \Gamma_{l}(z)}|f(x, k)| .
$$

Write $f^{*}(z)=m^{(0)} f(z)=\sup _{k}|(z, k)|$.

Let us suppose that $f(x, k) \rightarrow 0$ as $k \rightarrow \infty$ for each $x \in K$. Let $\|f\|_{p}=\sup _{k}\|f(\cdot, k)\|_{p}$ for $0<p<\infty$. It is shown in [10] that for $1<p<\infty$,

$$
A_{p}\|f\|_{p} \leqq\|S f\|_{p} \leqq B_{p}\|f\|_{p} \text { with constants } A_{p}, B_{p}>0 .
$$


It is easy to see that for $1<p<\infty$

$$
\|f\|_{p} \leqq\left\|f^{*}\right\|_{p} \leqq C_{p}\|f\|_{p} \text { with constant } C_{p}>0 \text {. }
$$

In other words,

$$
\|S f\|_{p} \approx\|f\|_{p} \approx\left\|f^{*}\right\|_{p} \text { for } 1<p<\infty .
$$

From [4], we have that, for all nonnegative $l$ and $h$,

$$
\begin{aligned}
\left\{x \in K: S^{(l)} f(x)<\infty\right\} & \cong\left\{x \in K: \lim _{k \rightarrow-\infty} f(x, k) \text { exists }\right\} \\
& \cong\left\{x \in K: m^{(h)} f(x)<\infty\right\}
\end{aligned}
$$

i.e., the above sets are equal except possibly for a set of measure 0 . Our main objective is to show that

$$
\left\|S^{(l)} f\right\|_{p} \approx\left\|m^{(h)} f\right\|_{p} \text { for } 0<p<\infty .
$$

As a consequence, we show that "nice" singular integral transforms preserve $H^{p}$-space $(0<p<\infty)$ which is the space of distributions whose maximal function are in $L^{p}$. The last result is the main contribution of [5].

The euclidean version of the main theorem can be found in [2] (see also [7]); its martingale version about $S f$ and $f^{*}$ is proved in [1]. Our work has been motivated by these results. In Appendix we shall discuss briefly how our argument can be applied to certain martingales.

REMARK 1. The equivalence in $L^{p}$ "norm" is interpreted in the obvious way, i.e., if one side is finite, so is the other and is bounded by a constant multiple of the former one. The restriction that $f(x, k) \rightarrow 0$ as $k \rightarrow \infty$ is needed only for the first inequality of (1) and $\left\|m^{(h)} f\right\|_{p} \leqq A_{p}\left\|S^{(l)} f\right\|_{p}$.

REMARK 2. A trivial modification gives us the same result for $K^{n}$, the $n$-dimensional vector space over $K$. The " $\Phi$-inequalities" of Burkholder-Gundy [1][2] for $S^{(l)}$ and $m^{(h)}$ could also be proved.

2. We first show that $\left\|f^{*}\right\|_{p} \approx\left\|m^{(l)} f\right\|_{p}$ for $0<p<\infty$.

Lemma 1. For $\lambda>0$, $\left|\left\{x \in K: f^{*}(x)>\lambda\right\}\right| \leqq\left|\left\{z \in K: m^{(l)} f(z)>\lambda\right\}\right| \leqq q^{l}\left|\left\{x \in K: f^{*}(x)>\lambda\right\}\right|$.

Proof. $\left|\left\{f^{*}>\lambda\right\}\right| \leqq\left|\left\{m^{(l)} f>\lambda\right\}\right|$ is obvious since $f^{*} \leqq m^{(l)} f$.

Suppose $m^{(l)} f(z)>\lambda$. Then there exists $(x, k) \in \Gamma_{l}(z)$ such that $|f(x, k)|>\lambda$. Hence $\mathscr{P}_{x}^{-k} \subset\left\{f^{*}>\lambda\right\}$ and $z \in \mathscr{P}_{x}^{-(k+l)}$. Therefore 


$$
\left|\left\{m^{(l)} f>\lambda\right\}\right| \leqq q^{l}\left|\left\{f^{*}>\lambda\right\}\right|
$$

THEOREM 1. $\left\|f^{*}\right\|_{p} \leqq\left\|m^{(l)} f\right\|_{p} \leqq q^{l / p}\left\|f^{*}\right\|_{p}$ for $0<p<\infty$.

Proof. This follows from Lemma 1 and the following identity:

$$
\|g\|_{p}^{p}=p \int_{0}^{\infty} \lambda^{p-1}|\{g>\lambda\}| d \lambda, \quad 0<p<\infty .
$$

Now let us break up the proof of $\left\|S^{(l)} f\right\|_{p} \approx\left\|m^{(h)} f\right\|_{p}(0<p<\infty)$ into several lemmas:

LeMmA 2. $\left\|S^{(l)} f\right\|_{2}^{2}=q^{l}\|S f\|_{2}^{2}=q^{l}\|f\|_{2}^{2}$.

Proof. Easy and known. (See Lemma 2.8(c) of [4].)

Lemma 3. $\left\|f^{*}\right\|_{p} \leqq A_{p}\|S f\|_{p}$ for $0<p<2$.

Proof. By (5), it suffices to show the following estimate:

$$
\left|\left\{f^{*}>\lambda\right\}\right| \leqq A \lambda^{-2} \int_{0}^{\lambda} t|\{S f>t\}| d t \text { for } \lambda>0 .
$$

For a fixed $\lambda>0$, let

$$
\sigma(x)=\sup \left\{n: S_{n} f(z)>\lambda \text { for some } z \in \mathscr{P}_{x}^{-(n+1)}\right\}
$$

where $S_{n} f(z)=\left(\sum_{k \geqq n}\left|d_{k} f(z)\right|^{2}\right)^{1 / 2}$. (Convention: $\sup \varnothing=-\infty$.) For $x \in K$ with $\sigma(x)=n$, let

$$
g(x, k)= \begin{cases}f(x, k) & \text { if } k \geqq n+1, \\ f(x, n+1) & \text { if } k \leqq n\end{cases}
$$

Hence $S g(x) \leqq \lambda$ and $S g(x) \leqq S f(x)$ for all $x$. Moreover, for $x \in$ $\{\sigma=-\infty\} \subset\{S f \leqq \lambda\}$, we have $g^{*}(x)=f^{*}(x)$ and $S g(x)=S f(x)$. On the other hand, suppose $\sigma(x)=n>-\infty$. Then there exists $z \in$ $\mathscr{P}_{x}^{-(n+1)}$ such that $S_{n} f(z)>\lambda$. Thus $\mathscr{P}_{z}^{-n} \subset\{z: S f(x)>\lambda\}$ with $x \in$ $\mathscr{P}_{z}^{-(n+1)}$. Therefore we have

$$
|\{x: \sigma(x)>-\infty\}| \leqq q|\{z: S f(x)>\lambda\}| .
$$

Now

$$
\begin{aligned}
\left|\left\{f^{*}>\lambda, \sigma>-\infty\right\}\right| & \leqq q|\{S f>\lambda\}| \\
& \leqq 2 q \lambda^{-2} \int_{0}^{\lambda} t|\{S f>t\}| d t
\end{aligned}
$$

and, by Lemma 2 and (5), 


$$
\begin{aligned}
\left|\left\{f^{*}>\lambda, \sigma=-\infty\right\}\right| & \leqq\left|\left\{g^{*}>\lambda\right\}\right| \leqq 2 \lambda^{-2}\|g\|_{2}^{2} \\
& =2 \lambda^{-2}\|S g\|_{2}^{2}=4 \lambda^{-2} \int_{0}^{\infty} t|\{S g>t\}| d t \\
& =4 \lambda^{-2} \int_{0}^{\lambda} t|\{S g>t\}| d t \\
& \leqq 4 \lambda^{-2} \int_{0}^{\lambda} t|\{S f>t\}| d t .
\end{aligned}
$$

Thus

$$
\begin{aligned}
\left|\left\{f^{*}>\lambda\right\}\right| & \leqq\left|\left\{f^{*}>\lambda, \sigma>-\infty\right\}\right|+\left|\left\{f^{*}>\lambda, \sigma=-\infty\right\}\right| \\
& \leqq(2 q+4) \lambda^{-2} \int_{0}^{\lambda} t \mid\{S f>t\} d t .
\end{aligned}
$$

This establishes (6) and Lemma 3.

Lemma 4. For $l>0$ and $0<p<2$,

$$
\left\|S^{(l)} f\right\|_{p} \leqq B_{p}\left\|m^{(l)} f\right\|_{p} .
$$

Proof. Again, it suffices to show that for $l>0$ and $\lambda>0$,

$$
\left|\left\{S^{(l)} f>\lambda\right\}\right| \leqq B \lambda^{-2} \int_{0}^{\lambda} t\left|\left\{m^{(l)} f>t\right\}\right| d t .
$$

Let $\mu(z)=\sup \left\{n:|f(x, n)|>\lambda\right.$ for some $\left.x \in \mathscr{P}^{-(n+l)}\right\}$. For $z \in K$ with $\mu(z)=n$, we have $\mu(x)=n$ for all $x \in \mathscr{P}_{z}^{-(n+l)}$; and let

$$
g(z, k)= \begin{cases}f(x, k) & \text { if } k \geqq n+1, \\ f(x, n+1) & \text { if } k \leqq n\end{cases}
$$

Hence $\{\mu=-\infty\}=\left\{m^{(l)} f \leqq \lambda\right\}$ and for $\mu(z)=-\infty$, we have $g(x, k)=f(x, k)$ if $x \in \mathscr{P}_{z}^{-(k+l)}$ or $(x, k) \in \Gamma_{l}(z)$. Thus on $\{z: \mu(z)=$ $-\infty\}, S^{(l)} g(z)=S^{(l)} f(z)$ and $m^{(l)} g(z)=m^{(l)} f(z) \leqq \lambda$. Now

$$
\begin{aligned}
\left|\left\{S^{(l)} f>\lambda, \mu>-\infty\right\}\right| & \leqq\left|\left\{m^{(l)} f>\lambda\right\}\right| \\
& \leqq 2 \lambda^{-2} \int_{0}^{\lambda} t\left|\left\{m^{(l)} f>t\right\}\right| d t,
\end{aligned}
$$

and by Lemma 2 and (5),

$$
\begin{aligned}
\mid\left\{S^{(l)} f>\lambda, \mu\right. & =-\infty\}|\leqq|\left\{S^{(l)} g>\lambda\right\} \mid \leqq \lambda^{-2}\left\|S^{(l)} g\right\|_{2}^{2} \\
& =q^{l} \lambda^{-2}\|g\|_{2}^{2} \leqq q^{l} \lambda^{-2}\left\|m^{(l)} g\right\|_{2}^{2} \\
& \leqq q^{l} \lambda^{-2} \cdot 2 \int_{0}^{\infty} t\left|\left\{m^{(l)} g>t\right\}\right| d t \\
& \leqq 2 q^{l} \lambda^{-2} \int_{0}^{\lambda} t\left|\left\{m^{(l)} f>t\right\}\right| d t
\end{aligned}
$$

Hence 


$$
\left|\left\{S^{(l)} f>\lambda\right\}\right| \leqq 2\left(q^{l}+1\right) \lambda^{-2} \int_{0}^{\lambda} t\left|\left\{m^{(l)} f>t\right\}\right| d t .
$$

Therefore Lemma 4 is proved.

Lemma 5. For $l \geqq 0$ and $2<p<\infty$,

$$
\left\|S^{(l)} f\right\|_{p} \leqq C_{p}\|f\|_{p} \text {. }
$$

Proof. Suppose $p>4$ and let $r$ be the conjugate index of $p / 2$. Thus $1<r<2$. Consider a fixed $k \in Z$. For $x \in K$, let $\left\{x_{i}\right\}_{i=1}^{q^{l}}$ be the distinct coset representatives such that $\mathscr{P}_{x_{i}}^{-(k-l+1)} \subset \mathscr{P}_{x}^{-(k+1)}$. For $g \in$ $L^{r}$ with $\|g\|_{r}=1$, we have

$$
\begin{aligned}
& \int_{K} \sum_{i=1}^{q^{l}}\left|d_{k} f\left(x_{i}\right)\right|^{2}|g(x)| d x=\sum_{i} \int_{K}\left|d_{k} f\left(x_{i}\right)\right|^{2}|g(x, k+1)| d x \\
& \quad=\sum_{i} \int_{K}\left|d_{k} f\left(x_{i}\right)\right|^{2}\left|g\left(x_{i}, k+1\right)\right| d x \\
& \quad=q^{l} \int_{K}\left|d_{k} f(x)\right|^{2}|g(x, k+1)| d x .
\end{aligned}
$$

Hence it follows from this, Hölder's inequality, (1) and (2) that

$$
\begin{aligned}
& \int_{K}\left[S_{n}^{(l)} f(x)\right]^{2}|g(x)| d x=\sum_{k \geqq n} \int_{K} \sum_{i=1}^{q^{l}}\left|d_{k} f\left(x_{i}\right)\right|^{2}|g(x)| d x \\
& \quad=\sum_{k \geq n} q^{l} \int_{K}\left|d_{K} f(x)\right|^{2}|g(x, k+1)| d x \\
& \quad \leqq q^{l} \int_{K}\left[S_{n} f(x)\right]^{2} g^{*}(x) d x \\
& \quad \leqq q^{l}\left\|S_{n} f\right\|_{p}^{2}\left\|g^{*}\right\|_{r} \\
& \quad \leqq B_{p}\|f\|_{p}^{2}
\end{aligned}
$$

where $B_{p}$ depends only on $p$ and $q$. Thus

$$
\begin{aligned}
\left\|S_{n}^{(l)} f\right\|_{p}^{2}=\left\|\left[S_{n}^{(l)} f\right]^{2}\right\|_{p / 2} & =\sup _{g \in L^{r},\|g\| r=1}\left|\int_{K}\left[S_{n}^{(l)} f(x)\right]^{2} g(x) d x\right| \\
& \leqq B_{p}\|f\|_{p}^{2} .
\end{aligned}
$$

Therefore $\left\|S^{(l)} f\right\|_{p} \leqq C_{p}\|f\|_{p}$ for $4<p<\infty$.

Apply the Marcinkiewicz interpolation theorem to this and Lemma 2 , we have

$$
\left\|S^{(l)} f\right\|_{p} \leqq C_{p}\|f\|_{p} \quad \text { for } \quad 2<p<\infty .
$$

Theorem 2. For $l, h \geqq 0$ and $0<p<\infty$,

$$
\left\|S^{(l)} f\right\|_{p} \approx\left\|m^{(h)} f\right\|_{p} .
$$

Proof. The case of $p=2$ is obvious. 
If $0<p<2$, then, from Lemma 3, Lemma 4 and Theorem 1 , we have for $l>0$,

$$
\begin{aligned}
\left\|f^{*}\right\|_{p} & \leqq A_{p}\|S f\|_{p} \leqq A_{p}\left\|S^{(l)} f\right\|_{p} \\
& \leqq A_{p} B_{p}\left\|m^{(l)} f\right\|_{p} \approx\left\|f^{*}\right\|_{p} .
\end{aligned}
$$

If $2<p<\infty$, then, by Theorem 1, (3) and Lemma 5 ,

$$
\begin{aligned}
\left\|m^{(h)} f\right\|_{p} & \approx\left\|f^{*}\right\|_{p} \approx\|f\|_{p} \approx\|S f\|_{p} \\
& \leqq\left\|S^{(l)} f\right\|_{p} \leqq C_{p}\|f\|_{p} .
\end{aligned}
$$

Therefore $\left\|S^{(l)} f\right\|_{p} \approx\left\|m^{(h)} f\right\|_{p}$ for $0<p<\infty$ and the proof of the theorem is completed.

REMARK 3. The above argument simplifies the extension argument as used in $\S 2$ of [4] and is essentially similar to the decomposition argument of [5]. It is also a sort of stopping time argument for martingales relative to a regular stochastic basis. (See Appendix.) The main result (with respect to "truncated cones") could be used to show (4)-the Fatou-Calderón-Stein theorem, in a similar manner as in [2].

3. Let $\pi$ be a (multiplicative) unitary character on $K^{*}$ such that it is homogeneous of degree 0 and is ramified of degree $h \geqq 1$. Denote $Q(x)=c \pi(x)|x|^{-1}$ where $c=1 / \Gamma(\pi)$. (See [9] for details about $\Gamma$-function.) Let $Q_{n}=R_{n} * Q$ and $Q_{n}^{N}=Q_{n} \Phi_{-N}$ for $N \geqq n+h$. For a distribution $f$ on $K$ or a regular function $f(x, k)$ on $K \times Z$, we note that $Q_{n}^{N} * f(x, k)=Q_{k}^{N} * f(x, k)=Q^{N} * f(x, k)$ for $n \leqq k \leqq N-h$. Define

$$
\left(T_{\pi} f\right)(x, k)=\lim _{N \rightarrow \infty} Q^{N} * f(x, k) \quad \text { for } \quad(x, k) \in K \times Z .
$$

If $f \in L^{p}(K), 1 \leqq p<\infty$, then this is just a sort of singular integral transform as been studied in [8], [11] and [4].

For $0<p<\infty$, let $H^{p}(K)$ be the space of all distributions $f$ on $K$ whose maximal function $f^{*} \in L^{p}(K)$ with the $H^{p}$ "norm" $\left\|f^{*}\right\|_{p}$. From [5], we know that for $f \in H^{p},\left(T_{\pi} f\right)(x, k)$ is a well-defined regular function. The regularization of the corresponding distribution is just $\left(T_{\pi} f\right)(x, k)$. Moreover, the following is also shown:

THEOREM 3. $T_{\pi}$ preserves $H^{p}$-spaces for $0<p<\infty$. That is, $\left\|\left(T_{\pi} f\right)^{*}\right\|_{p} \approx\left\|f^{*}\right\|_{p}$ for $0<p<\infty$.

We show here how this result can be obtained as a consequence of Theorem 2.

LeMma 6. $\quad S^{(h)} f(z)=S^{(h)} T_{\pi} f(z)$ for all $z \in K$. 
Proof. For a fixed $k \in Z$ and $x \in K$,

$$
d_{k} T_{\pi} f(x)=T_{\pi} f(x, k)-T_{\pi} f(x, k+1)=T_{\pi} d_{k} f(x) .
$$

For each $m \in Z$, let $\varepsilon_{m}^{i}, i=1,2, \cdots,(q-1) q^{h-1}$, be coset representatives of $\mathscr{P}^{-(m-h+1)}$ in $\left\{t:|t|=q^{m+1}\right\}$. Then

$$
\begin{aligned}
T_{\pi} f(x, k) & =c \int_{|t|>q k} f(x-t) \frac{\pi(t)}{|t|} d t \\
& =c \sum_{m=k}^{\infty} q^{-(m+1)} \int_{|t|=q^{m+1}} f(x-t) \pi(t) d t \\
& =c q^{-h} \sum_{m=k}^{\infty} \sum_{i=1}^{(q-1) q h-1} \pi\left(\varepsilon_{m}^{i}\right) f\left(x-\varepsilon_{m}^{i}, m-h+1\right) .
\end{aligned}
$$

Thus

$$
T_{\pi} d_{k} f(x)=c q^{-h} \sum_{i=1}^{(q-1) q^{h-1}} \pi\left(\varepsilon_{k}^{i}\right) f\left(x-\varepsilon_{k}^{i}, k-h+1\right) .
$$

Now let $g(x)$ be the restriction of $d_{k} f(x)$ on $z+\mathscr{P}^{-(k+1)}$ for any fixed $z$. Hence from (7) we see that $T_{\pi} g(x)$ is also supported on $z+$ $\mathscr{P}^{-(k+1)}$. By Plancherel's theorem, since $|\pi|=1$, we have

$$
\left\|T_{\pi} g\right\|_{2}=\left\|\left(T_{\pi} g\right)^{\wedge}\right\|_{2}=\left\|\pi^{-1} \hat{g}\right\|_{2}=\|\hat{g}\|_{2}=\|g\|_{2} \text {. }
$$

That is,

$$
\sum_{i=1}^{q^{h}}\left|d_{k} f\left(x_{i}\right)\right|^{2}=\sum_{i=1}^{q^{h}}\left|d_{k} T_{\pi} f_{\pi}\left(x_{i}\right)\right|^{2}
$$

where $x_{i}, i=1,2, \cdots, q^{h}$, are coset representatives of $\mathscr{P}^{-(k-h+1)}$ in $\mathscr{P}_{z}^{-(k+1)}$. Thus summing this up with respect to $k$, we have

$$
S^{(h)} f(z)=S^{(h)} T_{\pi} f(z)
$$

Proof of Theorem 3. It follows immediately from Theorem 2 and Lemma 6 that for $0<p<\infty$,

$$
\left\|f^{*}\right\|_{p} \approx\left\|S^{(h)} f\right\|_{p}=\left\|S^{(h)} T_{\pi} f\right\|_{p} \approx\left\|\left(T_{\pi} f\right)^{*}\right\|_{p} .
$$

Appendix. Let $(\Omega, \mathscr{A}, P)$ be a probability space and $\left\{\mathscr{A}_{n}\right\}_{n=1}$ a nondecreasing sequence of sub- $\sigma$-fields of $\mathscr{A}$. Let $f=\left\{f_{n}\right\}_{n \geqq 1}$ be a real-valued) martingale relative to $\left\{\mathscr{A}_{n}\right\}_{n \geq 1}$ and $\left\{d_{k}\right\}_{k \geq 1}$ be the difference sequence of $f$. For a nonnegative integer $l$, write

$$
m^{(l)} f=\sup _{n} E\left(\left|f_{n+l}\right| \mid \mathscr{A}_{n}\right)
$$

and $S^{(l)} f=\left[\sum_{k>l} E\left(d_{k}^{2} \mid \mathscr{A}_{k-l}\right)\right]^{1 / 2} . \quad f^{*}=m^{(0)} f=\sup _{n}\left|f_{n}\right|$ is the maximal function of $f$ and $S f=S^{(0)} f=\left[\sum_{k>0} d_{k}^{2}\right]^{1 / 2}$ is the square function of $f$. Burkholder and Gundy [1] proved that for a large class of 
martingales,

$$
\|S f\|_{p} \approx\left\|f^{*}\right\|_{p} \text { for } 0<p<\infty .
$$

However examples (in [1]) show that

$$
\left\|S^{(l)} f\right\|_{p} \approx\left\|m^{(h)} f\right\|_{p} \text { for } 0<p<\infty
$$

fails to hold. Nevertheless by a slight modification of the previous argument, we can show that this is true for martingales relative to a regular stochastic basis (after Chow [6]).

Indeed, the crucial part of the proof is to consider the following stopping time:

$$
\mu(x)=\inf \left\{n: E\left(\left|f_{n+l}\right| \mid \mathscr{X}_{n}\right)<\lambda\right\} \quad(\lambda>0) .
$$

Together with the regularity of the stochastic basis and (8), we get (9) by a similar argument as before.

We remark that our argument gives a simplified proof of (8) for martingales relative to a regular stochastic basis. Also the argument used in Lemma 5 similar to the one in [3] provides a new proof of that

$$
\|s f\|_{p} \leqq C_{p}\|f\|_{p} \text { for } \quad p>2
$$

where $s f=S^{(1)} f=\left[\sum_{k>1} E\left(d_{k}^{2} \mid \mathscr{A}_{k-1}\right)\right]^{1 / 2}$ is the conditioned square function of the martingale $f$ (relative to any stochastic basis).

\section{REFERENCES}

1. D. L. Burkholder and R. F. Gundy, Extrapolation and interpolation of quasi-linear operators on martingales, Acta Math., 124 (1970), 249-304.

2. - Distribution function inequalities for the area integral, Studia Math., 44 (1972), 527-544.

3. J.-A. Chao, A note on martingale square functions, Ann. Prob., 1 (1973), 1059-1060.

4. - $H^{p}$-spaces of conjugate systems on local fields, Studia Math., 49 (1974), 267-287.

5. - Maximal singular integral transforms on local fields, Proc. Amer. Math. Soc., 50 (1975), 297-302.

6. Y. S. Chow, Convergence of sums of squares of martingale differences, Ann. Math. Statist., 39 (1968), 123-133.

7. C. Fefferman and E. M. Stein, $H^{p}$-spaces of several variables, Acta Math., 129 (1972), 137-193.

8. K. Phillips and M. H. Taibleson, Singular integrals in several variables over a local field, Pacific J. Math., 30 (1969), 209-231.

9. P. J. Sally and M. H. Taibleson, Special functions on locally compact fields, Acta Math., 116 (1966), 279-309.

10. M. H. Taibleson, Harmonic analysis on $n$-dimensional vector spaces over local fields, II. Generalized Gauss kernels and the Littlewood-Paley function, Math. Ann., 186 (1970), 1-19.

11. —, III. Multipliers, Math. Ann., 187 (1970), 259-271.

Received February 20, 1975.

The University of TeXas at Austin 


\title{
PACIFIC JOURNAL OF MATHEMATICS
}

\section{EDITORS}

RichaRd ARENS (Managing Editor)

University of California

Los Angeles, California 90024

\section{R. A. Beaumont}

University of Washington

Seattle, Washington 98105
J. DUGUNDJI

Department of Mathematics University of Southern California Los Angeles, California 90007

D. Gilbarg and J. Milgram

Stanford University

Stanford, California 94305

\section{ASSOCIATE EDITORS}
E. F. BECKENBACH
B. H. NeUmanN
F. WOLF
K. YoshIDA

\section{SUPPORTING INSTITUTIONS}

\author{
UNIVERSITY OF BRITISH COLUMBIA \\ CALIFORNIA INSTITUTE OF TECHNOLOGY \\ UNIVERSITY OF CALIFORNIA \\ MONTANA STATE UNIVERSITY \\ UNIVERSITY OF NEVADA \\ NEW MEXICO STATE UNIVERSITY \\ OREGON STATE UNIVERSITY \\ UNIVERSITY OF OREGON \\ OSAKA UNIVERSITY
}

\author{
UNIVERSITY OF SOUTHERN CALIFORNIA \\ STANFORD UNIVERSITY \\ UNIVERSITY OF TOKYO \\ UNIVERSITY OF UTAH \\ WASHINGTON STATE UNIVERSITY \\ UNIVERSITY OF WASHINGTON \\ AMERICAN MATHEMATICAL SOCIETY
}

The Supporting Institutions listed above contribute to the cost of publication of this Journal, but they are not owners or publishers and have no responsibility for its content or policies.

Mathematical papers intended for publication in the Pacific Journal of Mathematics should be in typed form or offset-reproduced, (not dittoed), double spaced with large margins. Underline Greek letters in red, German in green, and script in blue. The first paragraph or two must be capable of being used separately as a synopsis of the entire paper. Items of the bibliography should not be cited there unless absolutely necessary, in which case they must be identified by author and Journal, rather than by item number. Manuscripts, in triplicate, may be sent to any one of the editors. Please classify according to the scheme of Math. Reviews, Index to Vol. 39. All other communications should be addressed to the managing editor, or Elaine Barth, University of California, Los Angeles, California, 90024.

The Pacific Journal of Mathematics expects the author's institution to pay page charges, and reserves the right to delay publication for nonpayment of charges in case of financial emergency.

100 reprints are provided free for each article, only if page charges have been substantially paid. Additional copies may be obtained at cost in multiples of 50 .

The Pacific Journal of Mathematics is issued monthly as of January 1966. Regular subscription rate: $\$ 72.00$ a year (6 Vols., 12 issues). Special rate: $\$ 36.00$ a year to individual members of supporting institutions.

Subscriptions, orders for back numbers, and changes of address should be sent to Pacific Journal of Mathematics, 103 Highland Boulevard, Berkeley, California, 94708.

PUBLISHED BY PACIFIC JOURNAL OF MATHEMATICS, A NON-PROFIT CORPORATION

Printed at Kokusai Bunken Insatsusha (International Academic Printing Co., Ltd.), 8-8, 3-chome, Takadanobaba, Shinjuku-ku, Tokyo 160, Japan.

Copyright (C) 1975 by Pacific Journal of Mathematics Manufactured and first issued in Japan 


\section{Pacific Journal of Mathematics}

\section{Vol. 59, No. $2 \quad$ June, 1975}

Aharon Atzmon, A moment problem for positive measures on the unit disc ........

Peter W. Bates and Grant Bernard Gustafson, Green's function inequalities for

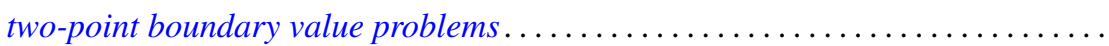

Howard Edwin Bell, Infinite subrings of infinite rings and near-rings ...........

Grahame Bennett, Victor Wayne Goodman and Charles Michael Newman, Norms of

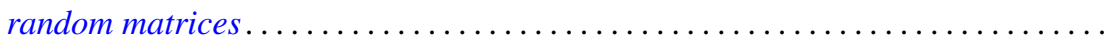

Beverly L. Brechner, Almost periodic homeomorphisms of $E^{2}$ are periodic.........

Beverly L. Brechner and R. Daniel Mauldin, Homeomorphisms of the plane ........

Jia-Arng Chao, Lusin area functions on local fields ......................

Frank Rimi DeMeyer, The Brauer group of polynomial rings ...............

M. V. Deshpande, Collectively compact sets and the ergodic theory of

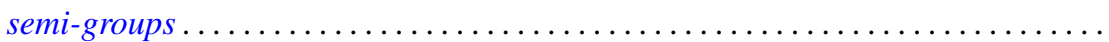

Raymond Frank Dickman and Jack Ray Porter, $\theta$-closed subsets of Hausdorff

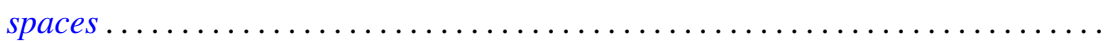

Charles P. Downey, Classification of singular integrals over a local field .......... 407

Daniel Reuven Farkas, Miscellany on Bieberbach group algebras . . . . . . . . . . . .

Peter A. Fowler, Infimum and domination principles in vector lattices . . . . . . . . . .

Barry J. Gardner, Some aspects of T-nilpotence. II: Lifting properties over

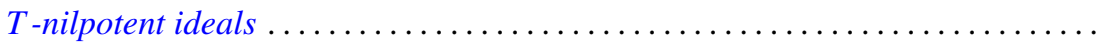

Gary Fred Gruenhage and Phillip Lee Zenor, Metrization of spaces with countable

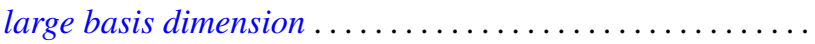

J. L. Hickman, Reducing series of ordinals...

Hugh M. Hilden, Generators for two groups related to the braid group ...

Tom (Roy Thomas Jr.) Jacob, Some matrix transformations on analytic sequence

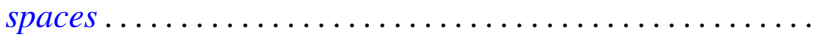

Elyahu Katz, Free products in the category of $k_{w}$-groups . .....

Tsang Hai Kuo, On conjugate Banach spaces with the Radon-Nikodým property...

Norman Eugene Liden, $K$-spaces, their antispaces and related mappings ...

Clinton M. Petty, Radon partitions in real linear spaces ........

Alan Saleski, A conditional entropy for the space of pseudo-Menger maps ....

Michael Singer, Elementary solutions of differential equations .

Eugene Spiegel and Allan Trojan, On semi-simple group algebras. I. . .

Charles Madison Stanton, Bounded analytic functions on a class of open Riemann

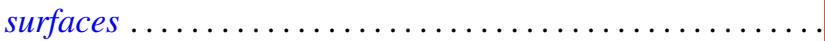

Sherman K. Stein, Transversals of Latin squares and their generalizations ....

Ivan Ernest Stux, Distribution of squarefree integers in non-linear sequences . . .

Lowell G. Sweet, On homogeneous algebras ................

Lowell G. Sweet, On doubly homogeneous algebras .......... .

Florian Vasilescu, The closed range modulus of operators ......

Arthur Anthony Yanushka, A characterization of the symplectic groups $\operatorname{PSp}(2 m, q)$

as rank 3 permutation groups... 